\title{
Motivational Interviewing: A Theoretical Framework for the Study of Human Behavior and the Social Environment
}

\author{
Katherine van Wormer
}

Abstract: This article provides a critical analysis of motivational interviewingstages of change model. Although rarely included in textbooks on human behavior and the social environment, this model has much to teach us about that aspect of human behavior most germane to social work practice-personal motivation for change of behaviors that are dysfunctional. The basic concepts that underlie motivational interviewing are derived from empirically-based principles from the science of social psychology. This article provides a historical and comparative approach to theory development, argues for the utility of this perspective as a guide to practice, and provides suggestions for further theory development.

\section{Keywords: Motivation, motivational interviewing, stages of change, human behavior and the social environment, cognitive approach, harm reduction}

$\mathrm{M}$ otivational interviewing (MI) is a brief treatment model designed to help clients who are low on motivation change- to help them wakeup to the need to change certain problematic behaviors-those that are healththreatening. MI may seem simple on the surface, but it is a very sophisticated modality based on advanced research knowledge from social psychology. MI is based on knowledge about how an individual's motivation to change can be enhanced by a practitioner, even when the client is reluctant to make any changes in his or her behavior (Gance-Cleveland, 2005). MI offers specific reinforcing maneuvers for every step of the way as the client advances, often in a spiraling fashion, toward change. Closely paralleling the strengths perspective in its underlying premises, motivational interviewing can be viewed as a developmental model in the spirit of the work of Erik Erikson (1950) and Carol Gilligan (1982). Like theirs, this model is stage-based or sequential. Unlike their formulations, however, $\mathrm{MI}$ is geared to direct practice; it is at once a theory and a therapy. The concern of this paper is with the theory dimension.

Motivational interviewing is defined by William Miller (2006) as "a person-centered, goal-oriented approach for facilitating change through exploring and resolving ambivalence" (p. 138). This term is most commonly used to represent a

Katherine van Wormer is professor at the School of Social Work at the University of Northern Iowa, Cedar Falls, IA 50614.

Copyright $^{\bullet} 2007$ Advances in Social Work Vol. 8 No. 1 (Spring 2007) 19-29.

Indiana University School of Social Work. 
series of pragmatic strategies tailored to the client's level of willingness to adjust his or her behavior (for example, to comply with a medical regimen, reduce criminality, or for smoking cessation (Miller \& Rollnick, 2002). These strategies have also been applied with favorable results in batterer intervention programming (Bennett, Stoops et al., 2007).

This paper provides a critical analysis of motivational theory and discusses the theoretical assumptions that underlie this approach. Where do these assumptions come from, and what are the research findings regarding its treatment effectiveness? Beginning with a historical analysis of the development of motivational theory, this paper demonstrates that the roots of this approach are found in the teachings of social psychology. That MI should be taught along with other developmental theories in HBSE courses is a further and related argument. Uniquely, this paper analyzes motivational concepts and insights that parallel empirically-based truths from the science of social psychology. Comparisons between this approach and its direct opposite-Samenow's confrontational cognitive approach-are drawn. This discussion leads into an overview of evidence-based research pertaining to this theoretical model. Finally, we explore some ideas for theory progression and implications for social work education.

\section{HISTORICAL ANALYSIS}

The concept of MI was first described by William R. Miller (1983) in the literature and elaborated by Miller and Rollnick (1991). Miller (1996) credited the formulation of MI to the relentless, spirited questioning by his student interns in Norway as he demonstrated how he would work with clients in various settings. The kind of questioning that ensued, ("Why have you taken this approach rather than another?"), according to Miller, required him to "make explicit the approach I had learned from my clients" (p. 835). The result was a beginning conceptual model (Miller, 1983) that was followed by years of testing and refinements, which culminated in the groundbreaking text Motivational Interviewing: Preparing People to Change Addictive Behavior (Miller, 1991).

With characteristic modesty, Miller and Rollnick later stated, "There is little that is highly original in motivation interviewing” (2002, p. xvi). For their inspiration, Miller and Rollnick credit the theoretical contributions of Carl Rogers and his students who developed the principles on which client-centered psychotherapy was based. The development of motivational theory took a major leap forward when it absorbed the notion that behavior change occurs in increments or stages and that it involves specific tasks related to the degree of an individual's willingness to change (DiClemente \& Velasquez, 2002). The impetus for theoretical advance came with the publication of the research on smoking cessation conducted by Prochaska and DiClemente (1982). Called the transtheoretical model, because it was interdisciplinary, the stages-of-change approach revealed the thinking patterns of smokers who eventually were able to quit. Their thinking was found to progress from precontemplation, before they were ready to change, to contemplation to quit, to preparation for action, to action, to maintenance, to possible relapse, and so on. Specific interventions have now been spelled out to match the client's stage of readiness to move from a refusal to cooperate to a decision to work on his or her problems. 
The trail for the wide acceptance of these conjoined models leads from the United States to Europe and back to this side of the Atlantic. Motivational concepts about instituting change were seen as compatible with the Western European goals of harm reduction or public health. Preventing drug users from contracting HIV-AIDS through the use of contaminated needles was the impetus here. The Netherlands, the United Kingdom, and Switzerland were among the nations that, in the 1980s, were at the forefront of this paradigm shift. The shift was away from a focus on punishment for drug use towards an emphasis on safety and persuasion.

Two developments in the United States promoted the advocacy of motivational therapy. The first was cross-fertilization of knowledge through international conferences on substance misuse. Through such exchanges, American social scientists began to grow familiar with principles of motivation and teach these concepts to their students. A second major development came with one of the most massive and best-publicized research experiments in substance abuse treatment history-Project MATCH. This research project is discussed in a later section of this paper.

\section{MOTIVATIONAL THEORY}

Motivational strategies, to reiterate, are built on sophisticated understandings of human behavior in the social environment (HBSE), most of which have been confirmed through real-life experimentation. The theoretical foundation of MI is first and foremost the knowledge that people often modify their behavior as a result of their interaction with others. A related assumption is that therapists who possess critical counseling skills can help facilitate personal change in their clients. Research indicates, for example, that one such skill, counselor empathy, can be a significant determinant of clients' response to treatment (Miller \& Rollnick, 2002). The four basic principles of enhancing motivation, as singled out by Miller and Rollnick, are: 1) expressing empathy; 2) developing discrepancy between one's long-term goals and one's behavior; 3) rolling with resistance (avoid arguing for change, which increases resistance); and 4) supporting self-efficacy - this refers to a person's belief in his or her ability to change.

Note that the first of these four principles is derived from Rogers' (1951) work in the area of empathic understanding of a client's previous behavior. As defined by Rogers, accurate empathy involves skillful reflective listening that clarifies and amplifies a person's presentation of reality. Unlike Rogers' extensive use of reflective listening, however, Miller and Rollnick's practice is to offer advice in terms of providing "a menu" of options. Also, in contrast to Rogers, motivational therapists use a cognitive approach to help clients see the discrepancy between their goals and present behavior (developing discrepancy is the second principle above).

Miller and Rollnick's reinforcement of their clients sense of confidence in their ability to overcome difficulty (fourth principle above) is a combination of the use of positive listening skills and reframing thoughts in a healthier direction, a cognitive-based strategy (van Wormer \& Davis, 2003). Through establishing a close therapeutic relationship, the counselor can help a person develop a commitment to change. 
The way motivational theory works, simply put: If the therapist can get the client to do something, anything, to get better, this client will have a chance at success. This is a basic principle of social psychology. Such tasks that William Miller (1998) pinpoints as predictors of recovery include: going to AA meetings, coming to sessions, completing homework assignments, and taking medication (even if a placebo pill). The question, according to Miller, then becomes, "How can I help my clients do something to take action on their own behalf?"

A related principle of social psychology is that, in defending a position aloud, as in a debate, we become committed to it. One would predict, according to motivational enhancement theory, that, if the therapist elicits defensive statements from the client, the client would become more committed to the status quo and less willing to change. For this reason, explains Miller, confrontational approaches have a poor track record. Research has shown that people are more likely to grow and change in a positive direction on their own than if they get caught up in a battle of wills.

The effectiveness of motivational strategies in eliciting change in even the most recalcitrant of people is worthy of closer analysis. Actually, the effectiveness of this model of person-centered counseling should come as no surprise, as each of the basic principles is derived from strategies that have been shown to be effective in social psychology laboratory situations. The overall technique of eliciting in the client self-motivating statement is perhaps the most basic of these scientific insights. I have filtered from one of the most popular books on social psychology, The Social Animal, by Elliot Aronson (2003), the basic principles of persuasion. The ones that most closely parallel the principles of motivational enhancement are:

- If we're encouraged to state a position, we become motivated to defend that position (p. 85).

- When individuals commit themselves in a small way, the likelihood that they will commit themselves further is increased. The behavior needs to be justified, so attitudes are changed (p. 158).

- People with high self-esteem are more likely to resist the temptation to commit immoral acts (p. 186).

- A person can become committed to a situation by making a decision, working hard to attain a goal (p. 186).

- Dissonance theory predicts that people will change their attitudes to bring them in line with the evidence (p. 189).

- Changing one's attitudes in order to justify one's behavior can initiate the processes that are persistent over time (p. 193).

- People desire dissonance-reducing behavior (p. 198).

Note that dissonance theory is comparable to this developing-discrepancy idea as enunciated by Aronson. In fact, as stated by Miller and Rollnick (2002), this idea was derived from classic sociological research on people's discontent with a discrepancy between their personal belief and the facts. A state of tension is thereby 
built-up and, out of this tension, comes the desire to end the dissonance. The therapist can take advantage of this state of ambivalence to lead the client in the direction of desirable change.

Also note that, when using motivational interviewing, practitioners are attempting to assist clients in talking themselves into changing, rather than using direct persuasion (Corcoran \& Springer, 2005). Resistance is sidestepped, so that it is not reinforced through "a battle of wills."

To gain an appreciation of how these theoretical premises are played out in practice and to learn how the development sequence works, let us consider the situation of an adolescent mandated to treatment for substance use problems. Following the formulation set forth by Miller and Rollnick (2002) and Wallen (1993), major tasks for the adolescent's counselor at each stage of decision making directly parallel the client's state of mind. At the precontemplation stage, the goals are to establish rapport, ask rather than tell, and build trust. Eliciting the young person's definition of the situation, the counselor reinforces discrepancies between the client's and others' perceptions of the problem. During the contemplation stage, while helping to tip the decision towards reduced drug/alcohol use, the counselor emphasizes the client's freedom of choice. "No one can make this decision for you" is a typical way to phrase this sentiment. Information is presented in a neutral, "take-it-or-leave-it" manner. Typical questions are: "What do you get out of drinking?" "What is the down side?" and (to elicit strengths) "What makes your sister believe in your ability to do this?" At the preparation for change and action stages, questions such as "What do you think will work for you?" will help to guide the youth forward without pushing him or her too far too fast. When there is resistance, as there inevitably will be with young substance misusers, Miller and Rollnick advise rolling with the resistance instead of fighting it. The use of reflective summarizing statements is helpful; for example, "Let's see if I've got this right. You have a concern that I'm trying to get you to give up smoking and drinking all at once. We do seem to be moving along too fast. Why don't we look at some things people have done in this situation, some of the options you might want to consider?" Central to this whole treatment strategy is the belief that clients are amenable to change and that timing is crucial in persuading clients to take the steps that will free them from harm.

On the college campus, the most promising type of intervention to address high-risk alcohol use (and ultimately reduce harm) appears to be a brief intervention with motivational interviewing. In Britain, New Zealand, and Canada, such brief sessions that promoted reflection on substance use and the personal consequences, have been shown in randomized controlled trials of high-risk students to reduce drinking and drug use significantly (Poulin, 2006).

\section{LINK TO HUMAN BEHAVIOR AND THE SOCIAL ENVIRONMENT}

Motivation is a key element in human (and much of non-human) behavior. Motivation drives us to get up in the morning, go to work, be productive, and control our impulses to do otherwise. Of course, there is motivation to engage in harmful, even criminal, practices as well. Motivation has to do with the human will to overcome daily obstacles and it is basic to our very survival. Accordingly, 
much of the psychology of human behavior is concerned with the motivation of individuals, while other social and behavioral sciences are concerned with the motivation of aggregates of people (to organize a mass movement, for example, or to conform to group norms).

Social work textbooks on human behavior typically include theories of development, theories that are often associated with crucial life stages. Motivation, however, (especially motivation to change) is not usually a part of the presentation. Motivational interviewing is discussed as a cognitive approach and also as a developmental life model of human behavior in van Wormer's (2007) Human Behavior and the Social Environment, but this is an exception to the rule. Since a major purpose of social work education is to provide background knowledge about human behavior to prepare students for practice, attention to factors related to the change effort are vital. What are turning points in a person's life? When does crisis produce worthwhile change? Which empirical findings from social psychology can serve to inform social workers how to help people who are in trouble turn their lives around? These are all research questions pertinent to those aspects of human behavior most relevant to social work practice. (They bear on policy issues as well, for example, in making a case for policy change, but that is a topic for another day.)

In any case, for HBSE textbooks to fail to cover such content, which directly links knowledge about modifying problematic behavior and how people get motivated to change, is a serious omission. In summary, motivational interviewing theory is highly relevant to the study of human behavior and should be covered as a developmental, stage-based model as a grounding for effective social work practice.

\section{EMPIRICAL RESEARCH}

Hester and Miller's (2003) Handbook of Alcohol Treatment Approaches is a research book that has been widely cited in the research field of alcoholism treatment in terms of the large scale comparisons of treatment outcomes. The first edition of this book was published in the 1980s. What these researchers learned was that the treatment methods with the strongest support of efficacy were virtually unknown and unused in U.S. standard practice. After their most recent review of hundreds of empirically-based clinical trials, the authors reached two major conclusions - there is no single superior approach to treatment for all individuals and treatment programs and systems should be constructed to include a variety of approaches, inasmuch as different individuals respond best to different approaches.

Of the 47 different treatment modalities that were tested in the literature, the top scores for measurable effectiveness were received for:

- brief intervention

- motivational enhancement

- the medications Acamprosate and Naltrexone

- self-control and social skills training 
- aversion therapy

- cognitive therapy

- acupuncture

The lowest rankings were received from worst to least bad by:

- education tapes, lectures, and films

- confrontational counseling

- relaxation training

- 12-step facilitation

The central message of this comparative study is that the widely used confrontational modalities are among those of little proven effectiveness. We should take into account, however, as Hester and Miller caution, the fact that some modalities, such as brief intervention and motivational enhancement, generally have been conducted with less seriously addicted populations than some of the others.

Directed by the National Institute on Alcohol Abuse and Alcoholism, the \$28 million multi-site, eight-year comparison study of 1997, known as Project MATCH, involved nearly 2,000 patients in the largest trial of psychotherapies ever undertaken. The three treatment designs chosen for this extensive study were based on the principles of the three most popular treatment designs-conventional Twelve-Step-based treatment, cognitive strategies, and motivational enhancement therapy (MET).

Although Project MATCH was designed to test the general assumption that matching could improve treatment outcomes, individuals were randomly assigned to three varieties of treatment, so that researchers could determine which modality worked best for whom. The results showed that one year and three years after treatment, former clients demonstrated substantial improvement, regardless of the modality used.

To the surprise of the research team, outcome evaluations showed that patienttreatment matching is not necessary for satisfactory results and that participants in the intensive Twelve-Step format did as well on follow-up as those in the cognitive-behavioral therapy and motivational enhancement designs. Treatments were provided over eight- and nine-week periods, with motivational therapy being offered only four times and the other two designs offering 12 sessions. All of the participants showed significant and sustained improvements in the increased percentage of days they remained abstinent and the decreased number of drinks per drinking day, the researchers said. However, the researchers noted that outpatients who received the Twelve-Step facilitation program were more likely to remain completely abstinent in the year following treatment compared to outpatients who received the other treatments. Individuals high on religiosity and those who indicated that they were seeking meaning in life generally did better with the Twelve-Step, disease-model focus, while clients with high levels of psychopathology did not do better with this approach. Clients low in motivation did best ultimately with the design geared for their level of motivation. 
In aftercare, in the subjects who were studied, less successful outcomes were associated with male gender, psychiatric problems, and peer group support for drinking. Because there was no control group who was deprived of treatment, generalizations concerning the efficacy of treatment cannot be made, a fact that has brought this massive project in for considerable criticism (Wallace, 2005). Another major criticism is that of selection bias in study recruitment. Clients who were dependent on heroin, cocaine, used IV drugs, and were suicidal or had acute psychoses were barred from the experimental treatment. Since the clients that counselors typically see are not as homogeneous and carefully screened, such restrictions affect generalization of the findings (Wallace, 2005). What this extensive, long-term study does show, however, is that all three individually delivered treatment approaches are relatively comparable in their results-that treatment that is not abstinence-based (motivational enhancement) is as helpful in getting clients to reduce their alcohol consumption as the more intensive treatment designs. These findings provide support for the guiding principle of this paper, which is to find what works in seemingly diverse treatment designs.

Project MATCH results showed that, for clients who scored high on measurements of anger, the motivational approach worked best, while for persons of a strong religious bent, the Twelve-Step approach was most effective. The MET sessions were fewer in number than were the cognitive or AA facilitation sessions; therefore, MET emerged as the most cost-effective, a fact that has not been lost by treatment centers or their sources for reimbursement, such as insurance companies (van Wormer \& Davis, 2008).

Burke, Arkowitz, and Menchola's (2003) meta-analysis of the efficacy of motivational interviewing clinical trials is also relevant for our purposes. Data were gathered from the literature of 30 controlled clinical trials that compared an adaptation of motivational techniques to another treatment format. The overall finding was that motivational adaptations showed equivalent benefits to other strategies but that they achieved the same results in far less time. The results were positive for problems involving alcohol, drugs, and diet, but less so for smoking and HIVrisk behaviors.

\section{SAMENOW'S CONFRONTATIONAL APPROACH}

Even as insurance companies favor brief motivational-based interventions for persons with substance abuse problems, correctional counselors and substance abuse treatment providers are often trained in techniques derived from Yochelson and Samenow (1977) and further elaborated by Samenow (2004). In common with motivational philosophy, Samenow and Yochelson's goal is the promotion of new ways of thinking in clients with behavioral problems. Both approaches draw on a cognitive approach to elicit behavioral change. Whereas Miller and Rollnick work in collaboration with clients to help them tap into latent strengths, Samenow's approach is decidedly negative, as the title of his most recent book, Inside the Criminal Mind, would indicate.

Based on his extensive work with psychopathic males who were institutionalized in a prison for the criminally insane, Inside the Criminal Mind tears down the theories of psychologists and sociologists and draws on multiple anecdotes in 
support of his position that the criminal uses addiction or a rotten childhood as an excuse to manipulate people, that he (there is no mention of females except as victims) is a victimizer who constantly seeks out people to exploit and cheat. Counseling is useless, because "any knowledge the criminal gleans from depth psychology he converts into excuses" (2004, p. 102). The recommended method is to show the client basically what a rotten person he is, then to force him to list his thinking errors and to correct them. The criminal is to identify himself as a criminal and use such self-talk as, "I am a criminal by nature and must control these natural tendencies." Unfortunately, workbooks based on this harsh confrontation approach are widely used in the substance abuse treatment field and by correctional counselors who work with both men and women, people who variously have been victims of others and/or themselves, and/or of cruel circumstances. Yet, research has consistently shown that harsh confrontational techniques are of limited effectiveness. As Miller and Rollnick (2002) indicate, "Counsel in a directive, confrontational manner, and client resistance goes up. Counsel in a reflective, supportive manner, and resistance goes down while change talk increases" (p. 9).

Contrast Samenow's accusatory style with the much more positive approach of motivational interviewing: In their seven-part professional training videotape series, W.R. Miller and Rollnick (1998) provide guidance in the art and science of motivational enhancement. In this series, the don'ts are as revealing as the do's. According to this therapy team, the don'ts, or traps for therapists to avoid, are:

- A premature focus, such as on one's addictive behavior

- The confrontational/denial round between therapist and client

- The labeling trap-forcing the individual to accept a label, such as alcoholic or addict

- The blaming trap, a fallacy that is especially pronounced in couples counseling

- The question/answer habit, characterized by asking several questions in a row and reliance on closed, yes-or-no responses; this exchange paves the way for the expert trap

- The expert trap, whereby the client is put down (the opposite of a collaborative exchange of information)

\section{IMPLICATIONS FOR SOCIAL WORK}

For favorable results in the change effort that is the essence of social work, knowledge of the fundamentals of motivation enhancement is crucial. The HBSE curriculum can promote such understanding through an inclusion of the principles of motivational interviewing theory-a developmental, stages-of-change model that could be studied alongside the stage models of Erikson and Gilligan.

The motivational stages-of-change model is rich with possibility of theoretical development. Barbara Wallace (2005), for example, has integrated this developmental model into a proposed training anti-racist scheme. When used with historically oppressed populations, (racial or sexual minorities), the focus is on pro- 
moting healthy identity development, and ethnic pride. For members of dominant groups, the focus at the pre-contemplation level is on motivating people who have a sense of racial superiority to work toward more mature feelings of self-pride and respect for diversity. Work to develop ethnic pride among minorities is probably less problematic (more likely to be well received by the client) than helping clients reduce their feelings of grandeur, homophobia, or racism. In either case, the focus is on maladaptive affective, behavioral, and cognitive responses and their replacement by less offensive and adaptive responses.

The flexible, client-centered, brief counseling approach of MI is consistent with social work's strengths perspective and the theme of harm reduction, "first do no harm." "Meet the client where the client is" is another commonly heard social work theme, one that can serve to summarize MI philosophy, as well. Motivational theory, finally, is consistent with NASW's policy statement that "adopting a comprehensive public health approach will enable social workers to focus on prevention and treatment of alcohol, tobacco, and other drug problems. This focus will prevent unnecessary stigma and will combat substance-related illnesses, disabilities, and premature death" (NASW, 2000, p. 23)

\section{References}

Aronson, E. (2003). The social animal. New York: Worth Publishers.

Bennett, L.W., Stoops, Call, C., \& Flett, H. (2007). Program completion and re-arrest in a batterer intervention system. Research on Social Work Practice, 17(1), 42-54.

Burke, B.L., Arkowitz, H., \& Menchola, M. (2003). The efficacy of motivational interviewing: A meta-analysis of controlled clinical trials. Journal of Consulting and Clinical Psychology, 71(5), 843-861.

Corcoran, J., \& Springer, D.W. (2005), In J. Corcoran (Ed.), Building strengths and skills: A collaborative approach to working with clients (pp. 131-162. New York: Oxford University Press.

DiClemente, C.C., \& Velasquez, M. (2002) Motivational interviewing and the stages of change. In W.R. Miller \& S. Rollnick (Eds.) Motivational interviewing: Preparing people for change ( ${ }^{\text {nd }}$ ed.) (pp. 201-216). New York: Guilford Publications.

Erikson, E. (1963). Children and society. New York: Norton.

Gance-Cleveland, B. (2005). Motivational interviewing as a strategy to increase families' adherence to treatment regimens. Journal for Specialists in Pediatric Nursing, 10(3), 151-155.

Gilligan, C. (1982). In a different voice: Psychological theory and women's development. Cambridge, MA: Harvard University Press.

Hester, R.K., \& Miller, W.R. (2003). Handbook of alcoholism treatment approaches: Effective alternatives ( ${ }^{\text {rd }}$ ed.). Boston: Allyn \& Bacon.

Miller, W.R. (1983). Motivational interviewing with problem drinkers. Behavioral Psychotherapy, 11, 147172 .

Miller, W.R. (1998). Enhancing motivation for change. In W.R. Miller \& N. Hester (Eds.), Treating addictive behaviors ( $2^{\text {nd }}$ ed., pp. 121-132). New York: Plenum Press.

Miller, W.R. (2006). Motivational factors in addictive behavior. In W.R. Miller \& K.M. Carroll (Eds.), Rethinking substance abuse: What the science shows (pp. 134-150). New York: Guilford Press.

Miller, W.R., \& Rollnick, S. (1991). Motivational interviewing: Preparing people to change addictive behavior. New York: Guilford Press. 
Miller, W.R., \& Rollnick, S. (2002). Motivational interviewing: Preparing people to change addictive behavior ( $2^{\text {nd }}$ ed.). New York: Guilford Press.

Miller, W.R., \& Rollnick, S. (1998). Motivational interviewing: Professional training videotape series. Directed by Theresa Moyers. University of New Mexico: Albuquerque.

National Association of Social Workers (NASW) (2000). Social work speaks: NASW policy statements 20002003 ( $5^{\text {th }}$ ed.) (pp. 32-40). Washington, D.C.: NASW.

Poulin, C. (2006, August) Harm reduction policies and programs for youth. Canadian Centre on Substance Abuse. Retrieved August 2006 from www.ccsa.ca.

Prochaska, J., \& DiClemente, C. (1992). In search of how people change: Applications to addictive behaviors. America Psychologist, 47, 1102-1114.

Project MATCH Research Group (1997, January). Matching alcoholism treatment to client heterogeneity: Project MATCH post-treatment outcomes. Journal of Studies on Alcohol, 58, 7-28.

Rogers, C.R. (1931). Client-centered therapy. Boston: Houghton-Mifflin.

Samenow, S. (2004). Inside the criminal mind (revised). Bethel, CT: Crown.

van Wormer, K., \& Davis, D.R. (2008). Addiction treatment: A strengths perspective. (2 ${ }^{\text {nd }}$ ed.) Belmont, CA: Brooks/Cole.

van Wormer, K. (2007). Human behavior and the social environment, micro level: Individuals and families. New York: Oxford University Press.

Wallace, B.C. (2005). Making mandated treatment work. Lantham, MD: Jason Aronson.

Wallen, J. (1993). Addiction in human development: Developmental perspective on addiction and recovery. New York: Haworth.

Yochelson, S., \& Samenow, S. (1977). The criminal personality, vol. 1. Lanham, MD: Jason Aronson.

\section{Author's Note:}

Address correspondence to: Katherine van Wormer, professor of Social Work, University of Northern Iowa, Sabin 36, Cedar Falls, IA 50614, USA. e-mail: vanworme@uni.edu. 